\title{
Evaluating $\alpha$-Synuclein's Interaction with Cellular Phospholipids and Potential Toxicity in Yeast Models for Parkinson's Disease
}

\author{
Lokesh Kukreja and Shubhik DebBurman \\ Biology Department \\ Lake Forest College \\ 555 N. Sheridan Road \\ Lake Forest, Illinois 60045 USA
}

Received: July 8, $2008 \quad$ Accepted: December 5, 2008

\begin{abstract}
Parkinson's disease is a progressive neurodegenerative disease caused by the death of midbrain dopaminergic neurons. The misfolding and aggregation of $\alpha$-synuclein plays a ruinous role in this disease, but how the protein becomes toxic is unclear. Using yeasts as model organisms for studying a-synuclein properties, our study explores the hypothesis that $\alpha$-synuclein toxicity depends on plasma membrane phospholipid binding. First, using a chemical approach, we induced phospholipid synthesis in both fission and budding yeast with dimethyl sulfoxide (DMSO), a known inducer [1]. Instead of regulating $\alpha$-synuclein-dependent toxicity, DMSO unexpectedly exerted its own toxicity in both yeasts, in addition to inducing a lethal morphology defect in budding yeast. Moreover, instead of inducing plasma membrane localization of a-synuclein in either yeast, DMSO altered a-synuclein localization in both yeasts into as-yet unidentified cytoplasmic structures. We speculate that some of these structures may be internal, membrane bound organelles. To test for membrane phospholipid binding specifically, a-synuclein localization was analyzed in a phosphatidylserine-deficient budding yeast strain. We observed no loss of plasma membrane localization, suggesting that other phospholipids may regulate such specificity to a-synuclein. Together, these related studies illustrate the usefulness of yeasts in evaluating genetic and environmental factors that regulate $\alpha$-synuclein toxicity linked to Parkinson's disease.

\section{INTRODUCTION}

Parkinson's disease (PD) is a progressive neurodegenerative movement disorder in which patients suffer from resting tremors, postural rigidity, bradykinesia, and poor balance. These symptoms are the result of the specific death of dopaminergic neurons in the substantia nigra pars compacta [2]. Most cases of PD are idiopathic and occur during late age. Approximately $10 \%$ of PD cases are genetically linked [3]. PD is fatal and incurable, but over the last thirty years a variety of drugs have been developed to treat the symptoms.

Key findings in PD research point to the hypothesis that the protein $\alpha$-synuclein plays a critical role in pathogenesis. PD is characterized by cytoplasmic accumulation

of misfolded a-synuclein, Lewy body, within the affected dying dopaminergic neurons [4]. There are three mutations in the $\alpha$-synuclein gene that cause dominant and familial PD; A53T [5], A30P [6], and E46K [7]. Transgenic mice [8] and flies [9] expressing the human form of $\alpha$-synuclein are well established models for replicating the PD phenotypes [10].

In recent years, the role of lipids has become significant in PD pathology. The interaction of $\alpha$-synuclein with lipids and vesicular membranes are evident in Lewy bodies [11-12]. a-Synuclein is found in lipidrich cytosolic fractions where the structure of amino and carboxyl termini of this protein share homology with fatty acid-binding proteins [13]. In the transgenic mouse model for PD, a-synuclein localizes primarily to the lipid-rich neuronal region of synaptosomes
\end{abstract}


[14]. In yeast, Saccharomyces cerevisiae, models, both WT and A53T a-synuclein localize to the plasma membrane [15-16]. When a-synuclein expression is elevated in the yeast, WT and A53T, but not A30P, are toxic to cells [15]. Yeast continues to serve as a good model system for PD. A screen of several thousand library clones in yeast identified 25 non-toxic $\alpha$-synuclein sequence variants [17]. Interestingly, most of these variants contain a mutation in the $\mathrm{N}$-terminal region to either proline or glutamic acid, which cause a defect in membrane binding. Hence, it is possible that toxicity arose by $\alpha$ synuclein binding directly to phospholipid membranes [17]. Moreover, the overexpression of $\alpha$-synuclein in yeast can lead to abnormal lipid accumulation [16], disrupt endocytosis $[16,18]$ and impair membrane trafficking in endoplasmic reticulum [19]. A genetic screen in budding yeast identified 86 genes that were lethal when absent with over-expressed a-synuclein [20]. Surprisingly, the two largest groups of these genes were involved in lipid metabolism and vesicle-mediated transport [20]. Previously, our lab has worked with both budding and fission yeast to model PD [21-22]. We also find that $\alpha$-synuclein localizes to the plasma membrane and exhibits cellular toxicity in budding yeast [21]. However, in fission yeast, $\alpha$-synuclein neither goes to the plasma membrane nor is it toxic [22].

Here, we further investigated the link between $\alpha$-synuclein's interaction with phospholipids and cellular toxicity using budding and fission yeast models. We developed two approaches; 1) chemical, using DMSO to up-regulate phospholipid synthesis, and 2) genetic, using a geneknockout budding yeast strain to downregulate phospholipid synthesis. We hypothesized that increasing phospholipid association of $\alpha$-synuclein would enhance cellular toxicity of the protein. We predicted that $\alpha$-synuclein in budding yeast would localize more to the plasma membrane in the presence of DMSO compared to cells left untreated. In fission yeast, we predicted that DMSO would decrease the formation of cytoplasmic aggregates and increase $\alpha$ synuclein's plasma membrane localization. Additionally, both yeasts would incur $\alpha$ synuclein dependent cellular toxicity in the presence of DMSO. In the knockout strain, we predicted a loss of $\alpha$-synuclein membrane localization with reduction in cellular toxicity.

\section{MATERIALS AND METHODS}

\section{a. S. Cerevisiae Expression Vectors}

The pYES2.1/V5-His-TOPO yeast expression vector (Invitrogen) was used for a-synuclein expression in budding yeast. The following two vector constructs were previously created for each experiment: green fluorescent protein (GFP), and wildtype $\alpha$-synuclein. $\alpha$-synuclein was tagged at the C-terminus with GFP. The pYES2.1/V5His-TOPO vector and the GFP tagged vector were used as expression controls.

\section{b. S. Pombe Expression Vectors}

Polymerase chain reaction (PCR) was used to amplify C-terminal green fluorescence protein (GFP)-tagged wild-type a-synuclein fusion cDNA from the $\alpha$ synuclein-GFP containing pYES2/TOPO $S$. cerevisiae vectors constructed by Sharma et al [21]:

forward primer, 5'GGGGCCAAGCTTGCCATGGATGTATTCA TGAAAGGA-3';

reverse primer, 5'-

\section{TTTGTAGAGCTCATACATGCCATG-3'.}

Similarly, PCR was used to amplify GFP cDNA from GFP-pYES/TOPO $S$. cerevisiae vectors constructed by Sharma et al. [21]:

forward primer, 5'CCCGGGACCATGGCCAGCAAAGGAGA AG-3';

reverse primer, $5^{\prime}-$ TTTGTAGAGCTCATACATGCCATG-3'.

These PCR products were subcloned, according to the manufacturer's protocol (Invitrogen), into fission yeast pNMT-1 TOPO-TA expression vector. The following two vector constructs were previously created for each experiment: GFP, and wild-type $\alpha$-synuclein. $\alpha$-synuclein was tagged at the $\mathrm{C}$-terminus with GFP. The pNMT-1 vector and GFP in pNMT-1 vector served as expression controls.

c. Yeast Strains

The TCP1 strain (h-leu1-32; Invitrogen) of fission yeast was kindly 
provided by Judy Potashkin, Rosalind Franklin University of Medicine and Science. BY4741 (MATa his3 $\Delta 1$ leu2 $\Delta 0$ met $15 \Delta 0$ ura3 $\Delta 0$ ) and cho1 $\Delta$ knockout strain were purchased from Open Biosystems.

\section{d. Yeast Transformation}

S. Pombe strains were transformed with pNMT TOPO-TA vectors [23] and $S$. Cerevisiae were transformed with pYES2.1/V5-His-TOPO vectors (see table 1.) using the lithium-acetate transformation method [24].

\section{e. S. Pombe Expression}

For selection, yeast cells were grown on synthetic-complete media lacking leucine (PDM-Leu). Presence of a-synuclein constructs was confirmed by polymerase chain reaction (PCR). The pREP vector, containing a thiamine repressible promoter, allowed for regulated $\alpha$-synuclein expression. Yeast cells were first grown overnight in PDM-Leucine (10uM thiamine) media at $30^{\circ} \mathrm{C}$. Cells were washed with water and diluted to log-phase $\left(5 \times 10^{\wedge} 6\right.$ cells $/ \mathrm{mL}$ ) in Edinburgh minimal medium (EMM) lacking thiamine media to induce expression and grown to the time points desired for various measurements.

\section{f. S. Cerevisiae Expression}

For selection, yeast cells were grown on synthetic-complete media lacking uracil (SC-Ura). Presence of $\alpha$-synuclein constructs was confirmed by polymerase chain reaction (PCR). The pYES2.1 vector, containing a galactose-inducible promoter (GAL1), allowed for regulated $\alpha$-synuclein expression. Yeast cells were first grown overnight in SC-Ura glucose (2\%) media at $30^{\circ} \mathrm{C}$. Cells were washed with water and diluted to log-phase $\left(5 \times 10^{\wedge} 6\right.$ cells $\left./ \mathrm{mL}\right)$ in SC-Ura galactose $(2 \%)$ media to induce expression and grown to the time points desired for various measurements.

\section{g. Fluorescence Microscopy}

Yeast cells were first grown overnight at $30^{\circ} \mathrm{C}$ in EMM containing thiamine (10uM) if working with $S$. Pombe or in SC-Ura glucose if working with $S$. Cerevisiae. After $24 \mathrm{hr}$, cells were pelleted at
$1500 \mathrm{~g}$ for 5 minutes, washed twice in $10 \mathrm{ml}$ $\mathrm{dH}_{2} \mathrm{O}$, resuspended in $10 \mathrm{ml}$ EMM without thiamine/SC-Ura galactose, of which $125 \mathrm{~mL}$ cells were used to inoculate $25 \mathrm{~mL}$ EMM without thiamine/SC-Ura galactose (to express $\alpha$-synuclein). At desired expression time points for microscopy, cells were harvested at $1500 \mathrm{~g}\left(4^{\circ} \mathrm{C}\right)$ for $5 \mathrm{~min}$ and were washed in $5 \mathrm{~mL}$ water. Then cells were resuspended in 100-1000 uL EMM+T/SCUra glucose, of which $10 \mathrm{uL}$ was pipetted onto a slide. Slide of cell culture was viewed using Nikon TE-2000U fluorescence microscope at 1000X magnification. Images were deconvoluted using MetaMorph software version 4.2. Cells were first viewed under differential interference contrast (DIC) microscopy, and then viewed for GFP fluorescence. For analysis, the number of cells in the field containing a-synuclein aggregates, intracellular structure localization or plasma membrane localization. The field was then moved three turns on the field control knob, and the process was repeated in a new field. At least 750 cells were evaluated for each sample. a-Synuclein phenotypes were scored as percent of total cells observed.

\section{h. Growth Curve}

Cells were grown in $5 \mathrm{ml}$ PDMLeu/SC-Ura glucose overnight at $30^{\circ} \mathrm{C}$ in the incubator which rotates at $200 \mathrm{rpm}$. Cells were harvested at $1500 \times \mathrm{g}$ for $5 \mathrm{~min}$ at $4^{\circ} \mathrm{C}$, and were washed twice in $5 \mathrm{ml} \mathrm{H}_{2} \mathrm{O}$. Cells were re-suspended in $5 \mathrm{ml} \mathrm{H} \mathrm{H}_{2} \mathrm{O}$ and were counted. Flasks with $25 \mathrm{ml}$ EMM/SC-Ura galactose were each inoculated with $2.0 \times 10^{6}$ cells $/ \mathrm{ml}$ density. At $0,6,12,18,24$, 36 and 48 hours, and in duplicate measurements, $1 \mathrm{ml}$ of cell culture was removed and placed in a cuvet to measure absorbance using a Hitachi U-2000 Spectrophotometer. Averaged absorbance readings were plotted against time points to produce a growth curve.

\section{i. Spotting Analysis}

For spotting, cells were grown to mid-log phase in PDM-Leu/SC-Ura glucose normalized to equal densities $(2 \times 107$ cells $/ \mathrm{mL}$ ), serially diluted (5-fold) into 96 -well microwell plates. Using a multi-channel pipettor, culture is spotted on EMM + 


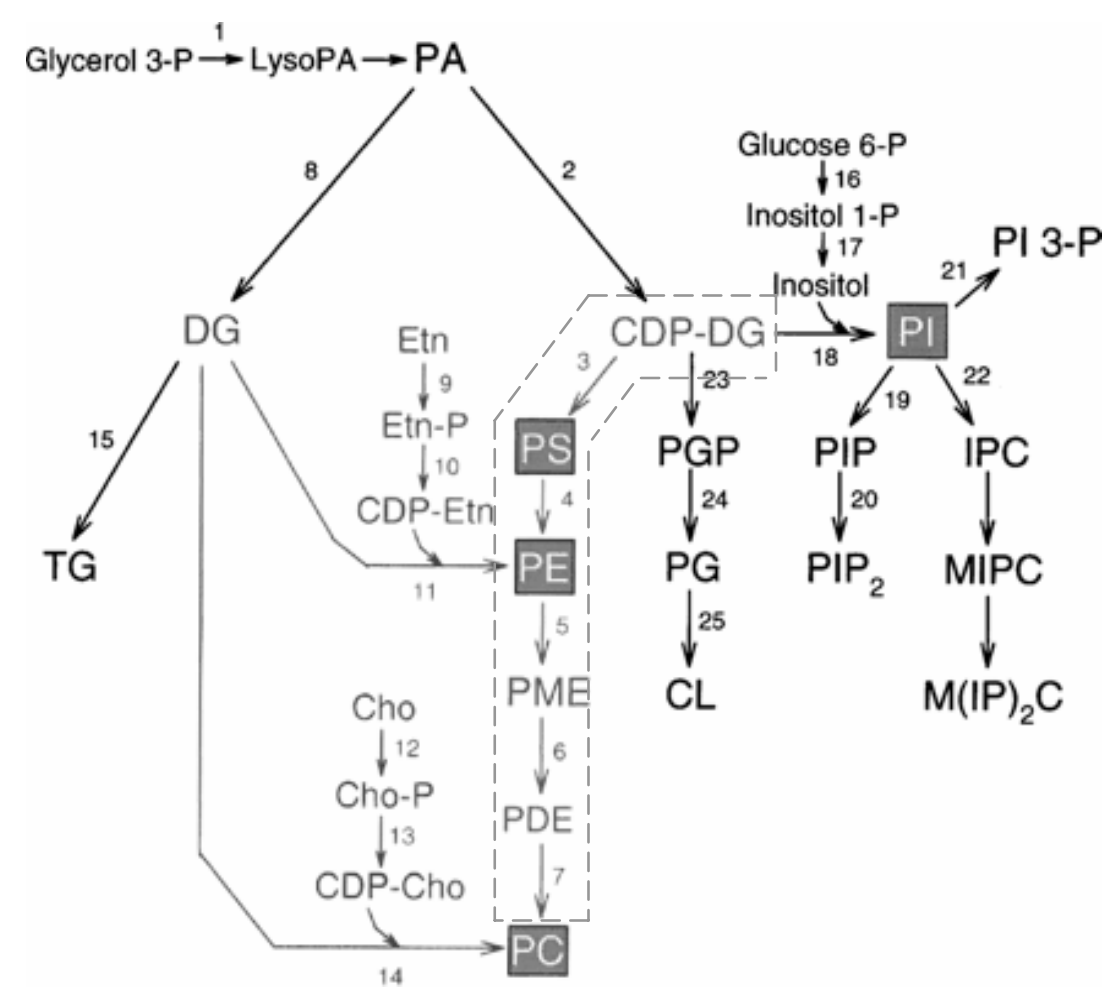

Figure 1. Phospholipid biosynthetic pathways in Saccharomyces cerevisiae. Reaction 3, in our study, is terminated due to the absence of PS synthase. The four major phospholipids (PC, PE, $\mathrm{PI}$, and PS) are indicated by boxes [25].

thiamine or EMM - thiamine plates ( $S$. Pombe) and SC-Ura glucose or galactose plates (S. Cerevisiae). Photographs of the plates were scanned after 2 days of growth.

\section{j. Western Analyses}

Yeast cells $\left(2.5 \times 10^{7}\right.$ cells $\left./ \mathrm{mL}\right)$ were washed in $50 \mathrm{mM}$ Tris (pH 7.5) and $10 \mathrm{mM}$ $\mathrm{NaN}_{3}$ and solubilized in electrophoresis sample buffer ([ESB] Burke et al [24]) containing $2 \%$ sodium dodecyl sulfate (SDS), $80 \mathrm{mM}$ Tris (pH 6.8), 10\% glycerol, $1.5 \%$ dithiothreitol, $1 \mathrm{mg} / \mathrm{mL}$ bromophenol blue, and a cocktail of protease inhibitors and solubilizing agents (1\% Triton X-100, 1 $\mathrm{mM}$ phenylmethylsulfonyl fluoride, $1 \mathrm{mM}$ benzamidine, $1 \mathrm{mM}$ sodium orthovanadate, $0.7 \mu \mathrm{g} / \mathrm{mL}$ pepstatin A, $0.5 \mu \mathrm{g} / \mathrm{mL}$ leupeptin, $10 \mu \mathrm{g} / \mathrm{mL}$ E64, $2 \mu \mathrm{g} / \mathrm{mL}$ aprotinin, and 2 $\mu \mathrm{g} / \mathrm{mL}$ chymostatin). Samples were run on precast $10-20 \%$ Trisglycine gels (Invitrogen) using SDS containing running buffer. SeeBlue (Invitrogen) was used as the molecular standard. Gels were transferred to
PVDF membranes, and Western blot was performed with different monoclonal antibodies using standard protocols and detected for alkaline phosphatase activity: anti-V5 (Invitrogen) for most blots to probe for a-synuclein, and anti-phosphoglycerokinase ([PGK] Molecular Probes) and Anti $\beta$-Actin (Abcam) for most expression experiments, as a measure of loading control in duplicate blots.

\section{k. Analysis on cho1 $1 \Delta$ strain}

The deficiency in phospholipid content was produced using a knocked out yeast strain that lacks the gene $\mathrm{CHO} 1$ which encodes for phosphatidylserine synthase. The phospholipid biosynthetic pathway (see Figure 1; adapted [25]) in yeast is a reference for understanding how specific phospholipid-deficient state is established. For this study, the main pathway of import is surrounded with dashed boxes and is termed the de novo pathway for synthesis of PS, PE and phosphotidycholine (PC). The 


\section{A. Growth Curve}
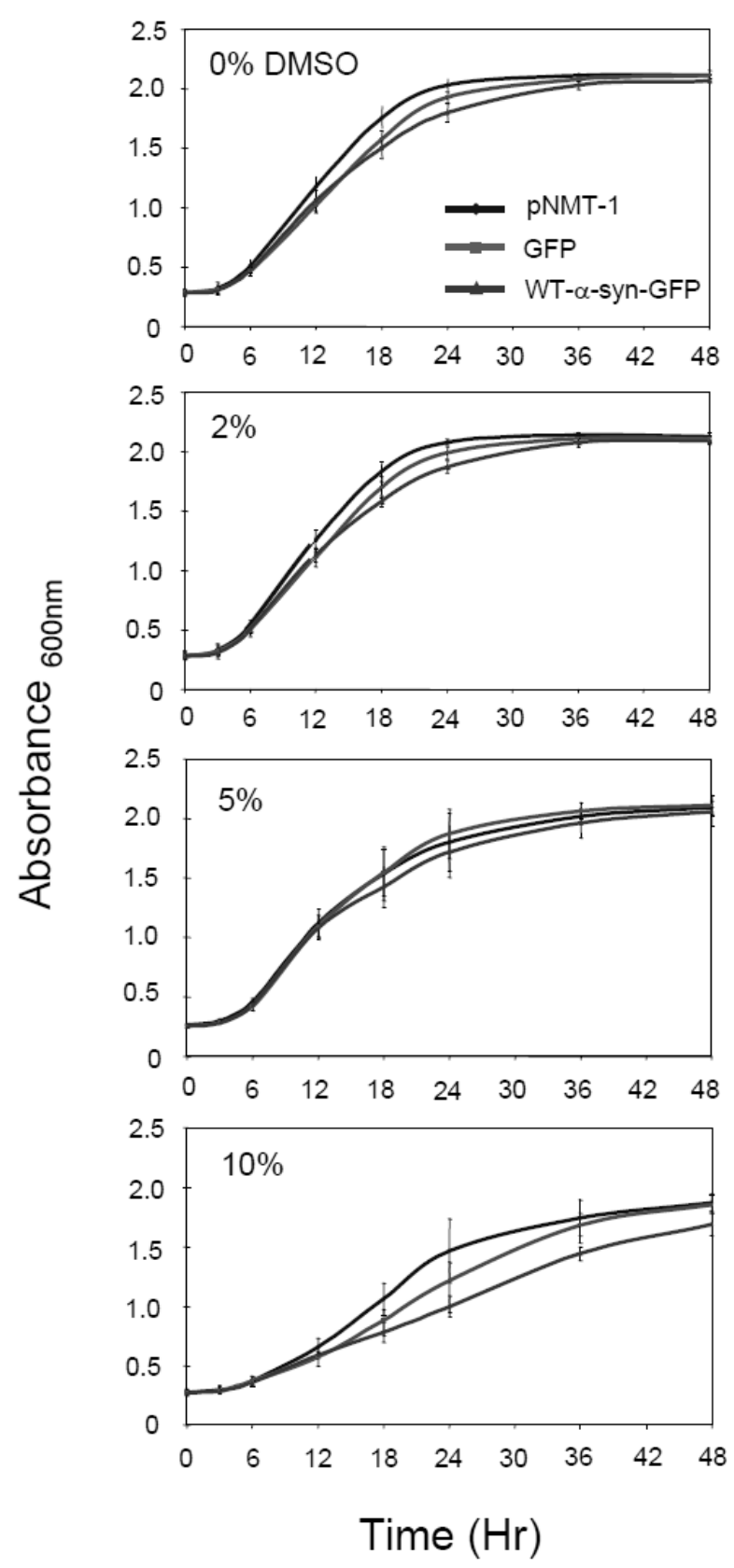

B. Spotting
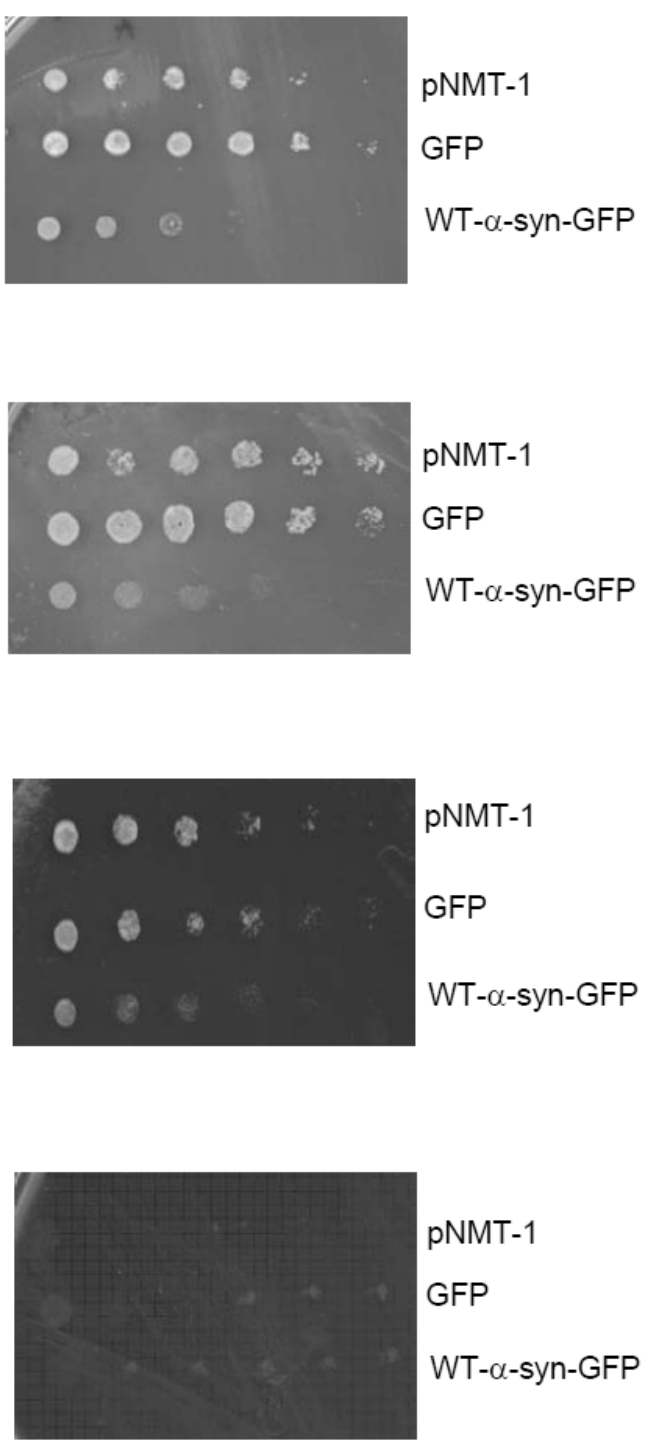

Figure 2. Fission yeast treated with DMSO. A. Growth Curve: Fission yeast were grown in EMMT for 48 hours expressing WT (wild-type) a-synuclein along with pNMT-1 parent plasmid and GFP as controls. Over this time course, cells were treated with $2 \%, 5 \%$ or $10 \%$ DMSO and compared to the cells that were not treated. Each of the points on the curves represents the mean from three trials on measurement of absorbance. In addition, the standard error of the mean for a $95 \%$ confidence interval is represented by the y-bar on each of the points on the growth curves. Significant growth difference exists between pNMT-1 in 0\% DMSO $(n=3, p 18 \mathrm{hr}=$ 0.007 and p24hr= 0.098) and pNMT-1 in 10\% DMSO. B. Spotting: Serially diluted cells expressing parent pNMT-1 plasmid, GFP, or WT a-synuclein were spotted onto EMM-T (inducing) plates. This experiment was repeated two separate times. 


\section{A. Microscopy}

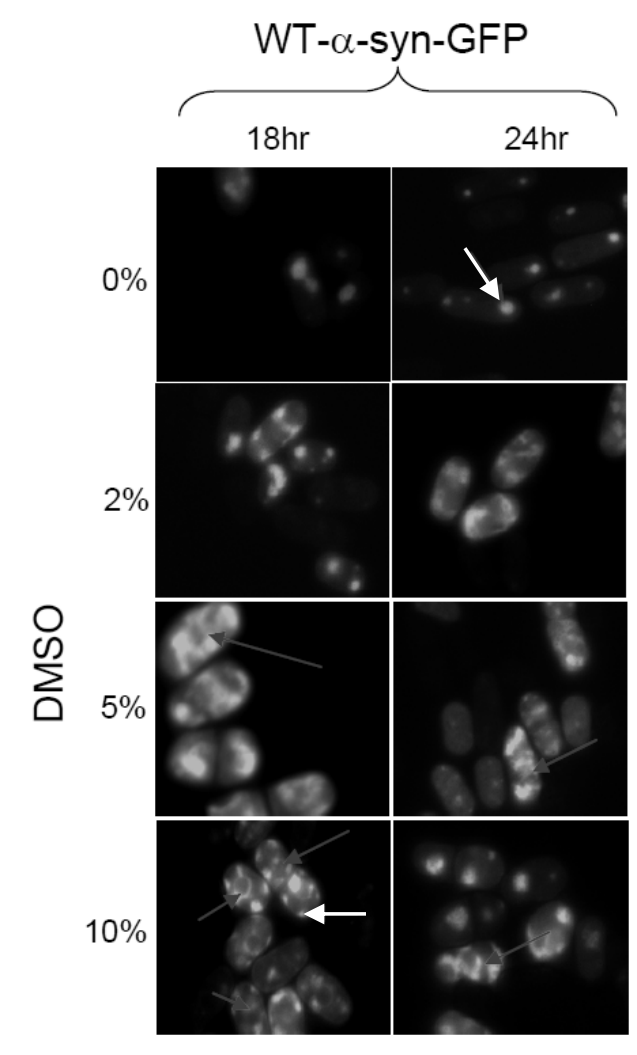

C. Expression

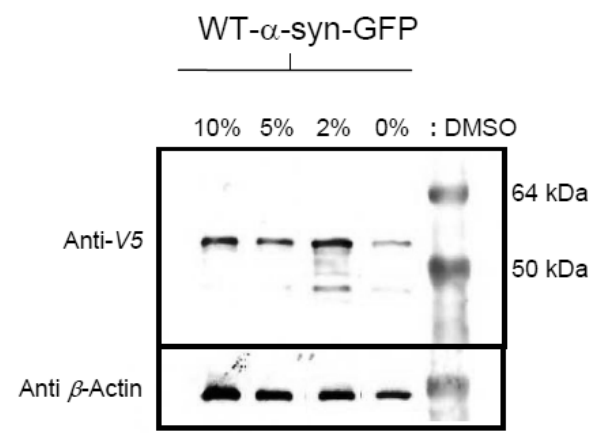

\section{B. Quantification}

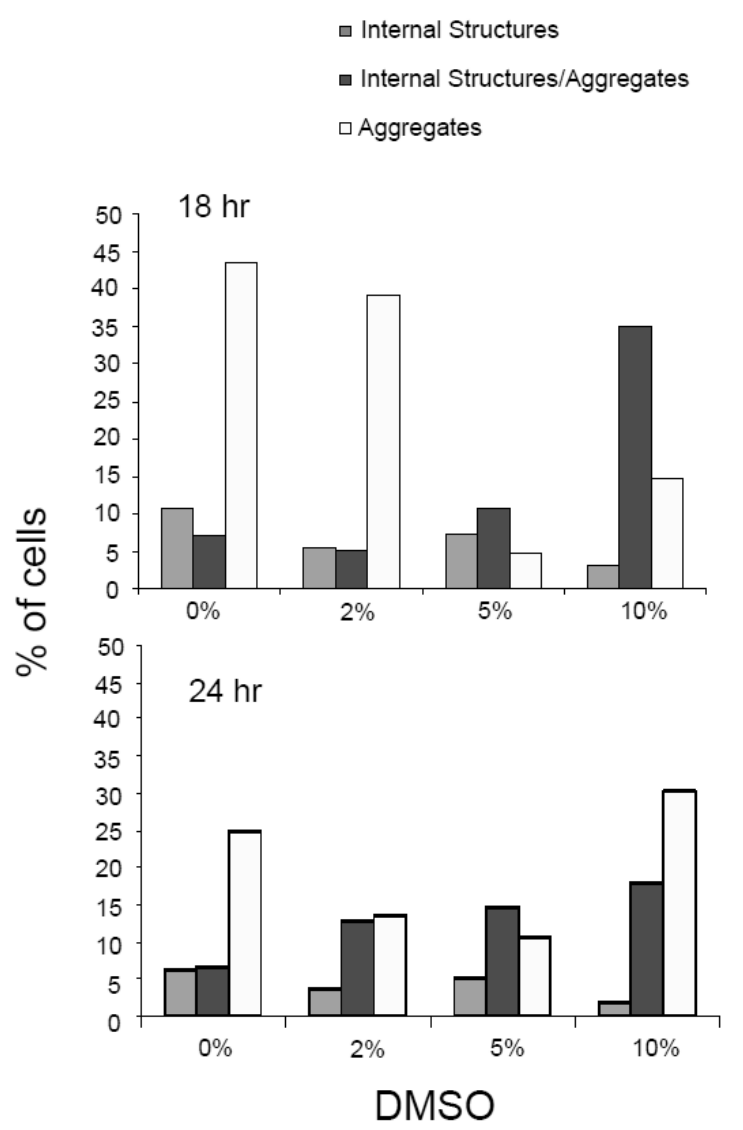

Figure 3. GFP Microscopy and a-synuclein expression in fission yeast cells treated with DMSO. A. Microscopy: Images were captured at 18 and 24 hours after induction in EMM-T. Aggregates (white arrow) in these cells started to form at 18 hours. With increasing concentrations of DMSO, a-synuclein began to localize to intracellular structures (gray arrow). B. Quantification: Cells expressing WT- $\alpha$-synuclein were counted and characterized by the following phenotypes: internal structure localization (light gray bar), internal structure localization and aggregates (dark gray bar), or aggregates (white bar). Bars represent the percent of 600-800 total cells which display those various a-synuclein phenotypes at different concentration of DMSO. C. Expression: For all the samples, $\alpha$-synuclein expression was induced for $24 \mathrm{hr}$ in EMM-T media and detected using anti-V5. Anti $\beta$-Actin antibody showed equal loading of protein. 
gray pathways, called the Kennedy pathway, are for using exogenous choline or ethanolamine to produce those phosphorlipids. The parent strain is BY4741. To stop PS production (it would still have all the rest of the phospholipids if ethanolamine present), we grew cho1s yeast strain in 1 $\mathrm{mM}$ ethanolamine in every selected media. Protocols written above for $S$. cerevisiae experiments such as growth curve, and fluorescence microscopy were followed.

\section{Statistical Analyses}

Statistical significance was established using a T-Test comparing the means of control cells containing no $\alpha$ synuclein at 18 and 24 hours in treated versus untreated conditions.

\section{m. DMSO Treatment}

Dimethyl sulfoxide (DMSO) was purchased from Sigma-Aldrich. Cells were grown in $10 \mathrm{ml} \mathrm{PDM-leu}$ or in SC-Ura glucose overnight at $30^{\circ} \mathrm{C}$. Procedure for cell harvesting and calculating cell density for inoculation was done according to the appropriate experiment discussed above. DMSO was added to the selected media at concentrations of $0 \%, 2 \%, 5 \%$ and $10 \%$. Afterwards, yeast cells were inoculated into the media. Then the cells were observed at the desired time points for the following experiments: Western Analysis, Growth Curve, Spotting Analysis and Fluorescence Microscopy.

\section{RESULTS}

a. DMSO induces $\alpha$-synuclein independent toxicity in fission yeast

Our first goal was to evaluate if a global induction of phospholipid synthesis would increase a-synuclein-dependent toxicity in fission yeast. We used a known phospholipid inducer in yeast, the organic solvent DMSO [1]. Toxicity was assessed in two ways. First, OD600 growth curves were performed on cells with or without $\alpha$ synuclein and with DMSO treatment. As previously reported [22], without DMSO $\alpha$ synuclein expressing cells grew well (Figure
2A). However, with DMSO cells were toxic in a concentration dependent manner (Figure $2 A)$. Surprisingly, this toxicity was not $\alpha$ synuclein dependent, cells that expressed GFP alone or contained the parent vector were also growth impaired (Figure 2A). aSynuclein, at best, enhanced DMSO toxicity minimally (Figure 2A). Secondly, we evaluated colony survival on plates by serial dilution. Similar to growth curve analysis, we observed a striking dose-dependent toxicity with DMSO that was not dependent on the presence of $\alpha$-synuclein (Figure 2B). Together, both toxicity assays indicate that DMSO exerted an unexpected toxicity in fission yeast independent of $\alpha$-synuclein presence.

b. DMSO alters $\alpha$-synuclein localization to internal structures in fission yeast

Next, we evaluated if DMSO would induce plasma membrane localization of $\alpha$ synuclein in fission yeast. Localization was assessed by live cell GFP imaging. As previously reported [22], wild-type $\alpha$ synuclein in fission yeast showed cytoplasmic aggregates (Figure 3A). DMSO induced $\alpha$-synuclein to alter its localization to internal cellular structures (Figure $3 \mathrm{~A}$ ). Upon quantification, we determined that with increasing DMSO concentration, a greater percent of cells began to display $\alpha$-synuclein localization to internal cellular structures (Figure 3B). However, the expression of $\alpha-$ synuclein remained the same with DMSO treatment (Figure 3C).

c. DMSO also induces $\alpha$-synucleinindependent toxicity in budding yeast

We conducted parallel studies in budding yeast using the strain BY4741, and asked if DMSO would increase $\alpha$-synucleindependent toxicity. First, OD600 growth curves were performed on cells with or without $\alpha$-synuclein expression and treated them with DMSO. a-Synuclein expressing cells, without DMSO, exhibited slight toxicity (Figure 4A). However, as DMSO concentration increased, especially at $10 \%$, the growth curve shifted significantly to the right, indicating a toxic effect (Figure 4A). Toxicity was not specific to a-synuclein; cells 


\section{A. Growth Curve}
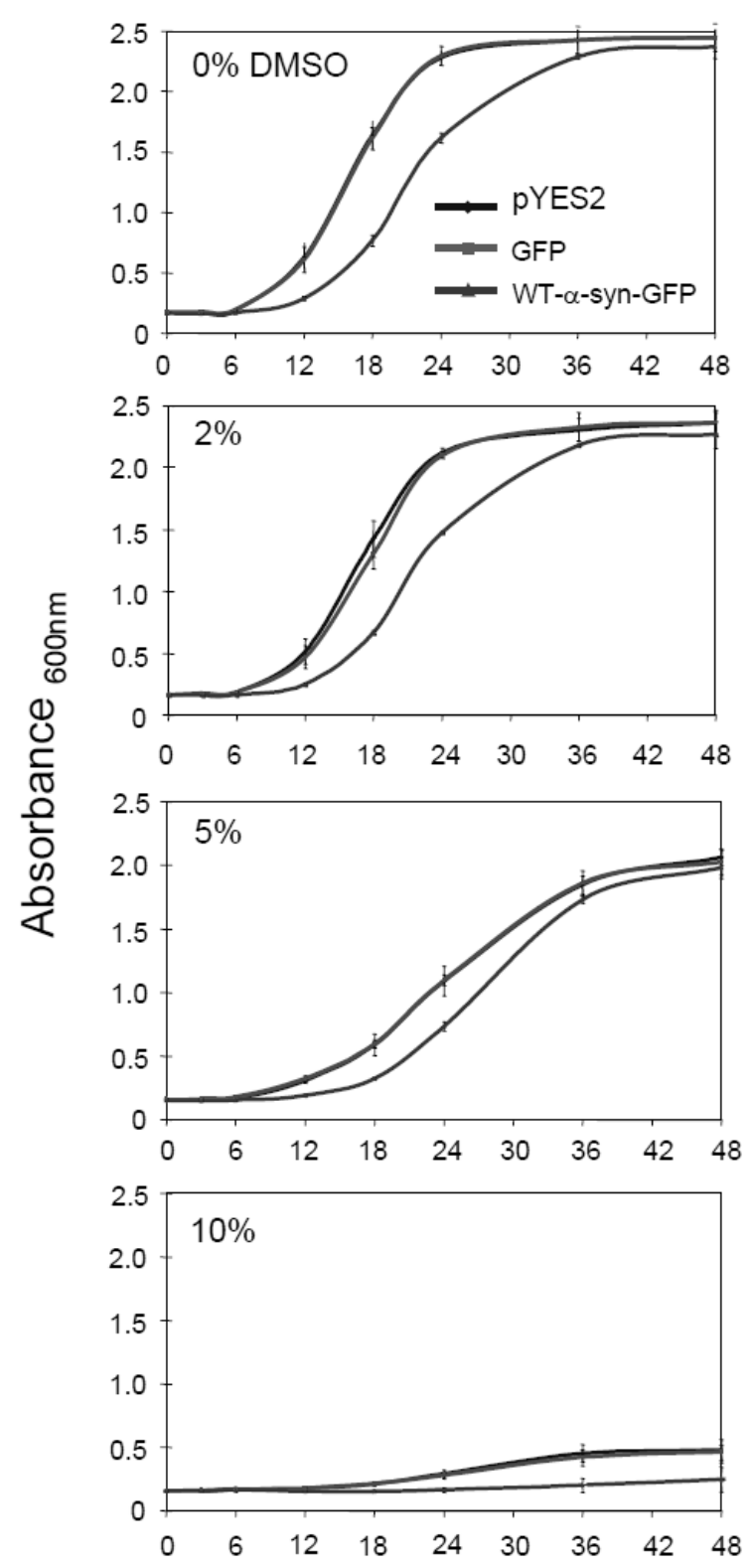

Time $(\mathrm{Hr})$

\section{B. Spotting}
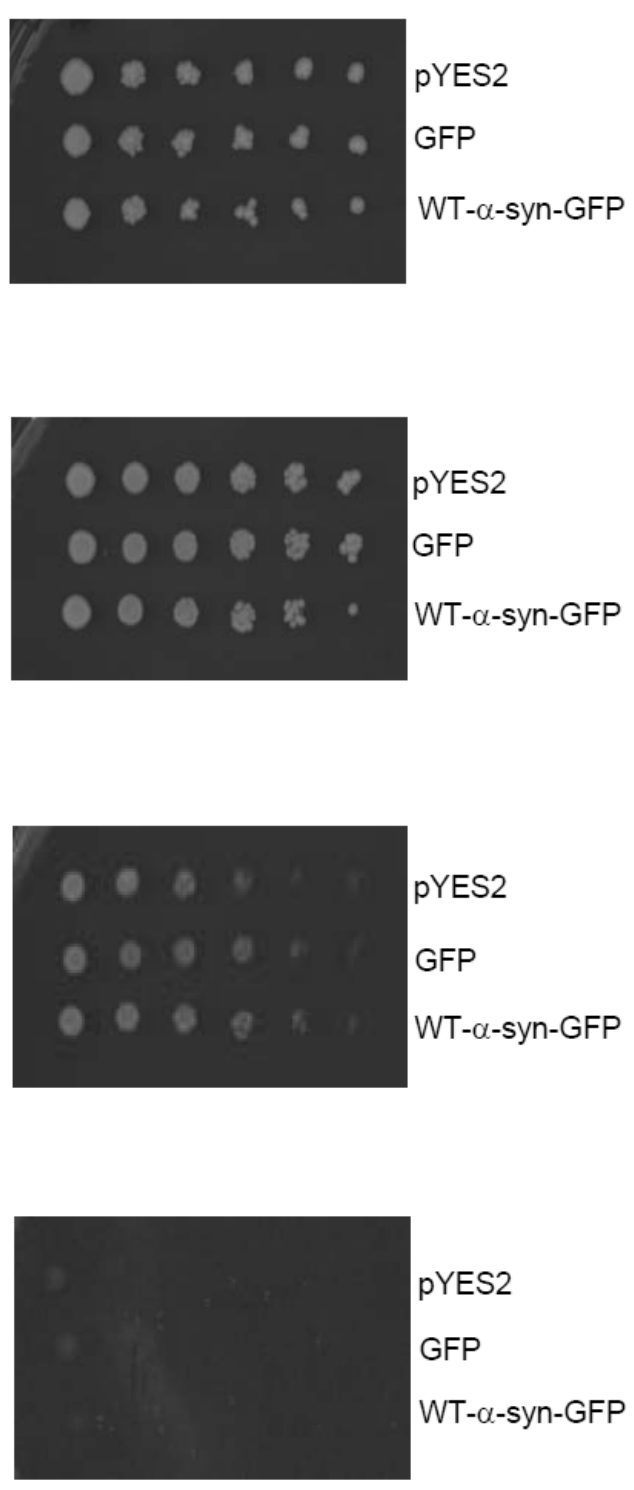

Figure 4. Budding yeast BY4741 treated with DMSO. A. Growth Curve: BY4741 cells were grown in Sc-Ura galactose for 48 hours to induce parent pYES2 plasmid, GFP, and WT a-synuclein. Over this time-course, cells were treated with $2 \%(\mathrm{~A}), 5 \%$ (B) or $10 \%(\mathrm{C})$ DMSO (dashed lines) and compared to the cells that went without DMSO treatment (solid lines). Each of the points on the curves represents the mean from three trials on measurement of absorbance. In addition, the standard error of the mean for a 95\% confidence interval is represented by the y-bar on each of the points on the growth curves. Significant growth difference exists between pYES2 in $0 \%$ DMSO $(n=3, p 18 h r=0.004$ and $p 24 h r=0.0005)$ and pYES2 in $10 \%$ DMSO. B. Spotting: Serially diluted cells expressing parent pYES2 plasmid, GFP, or WT a-synuclein were spotted onto SCUra galactose (inducing) plates. This experiment was repeated two separate times. 


\section{A. Evaluating Sugar Dependence}
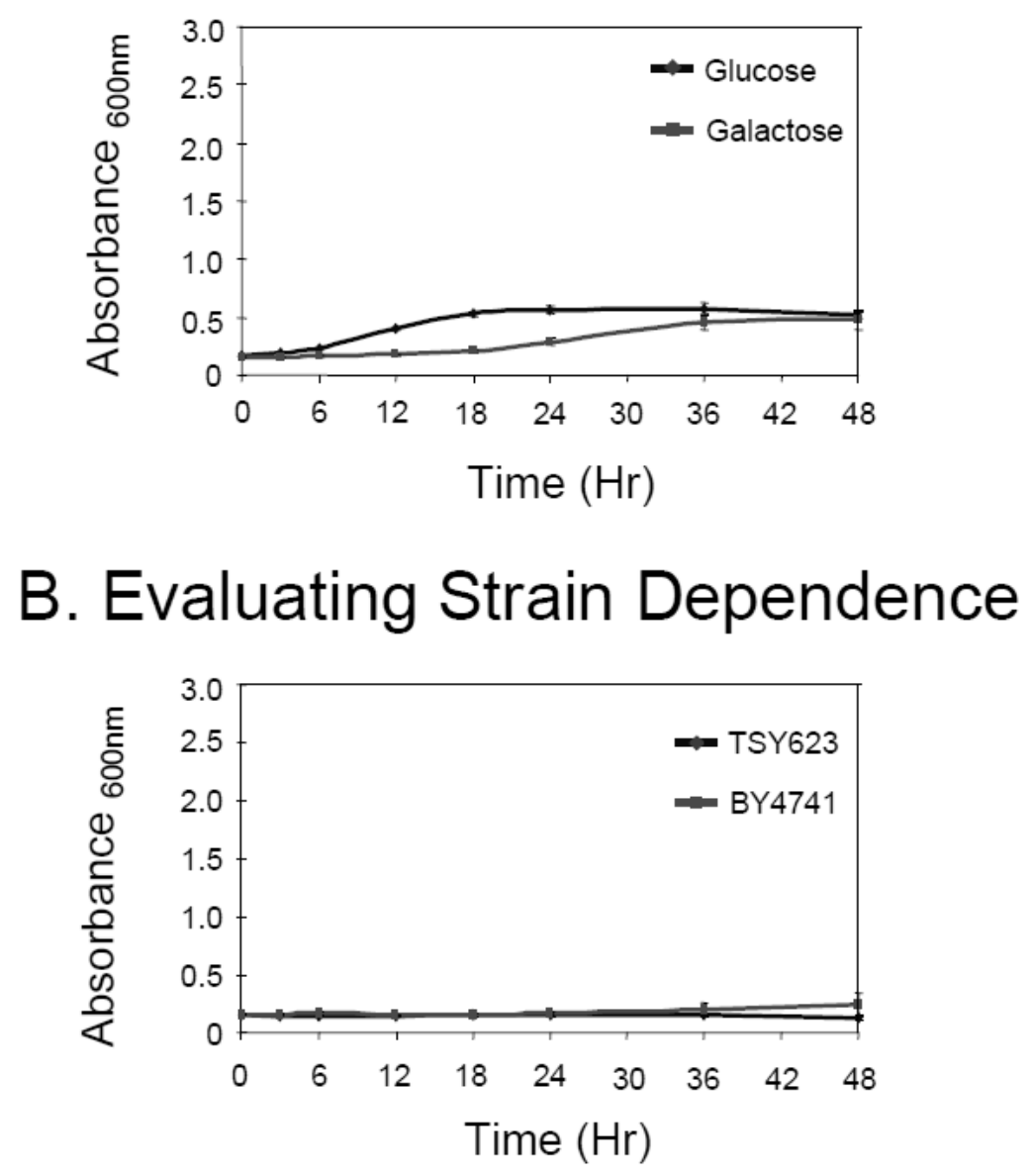

Figure 5. Budding yeast toxicity analysis with DMSO. A. Evaluating Sugar Dependence: BY4741 budding yeast cells with parent plasmid were grown in SC-Ura galactose and glucose media to test if slow growth in $10 \%$ DMSO is partially due to change of sugar in the media. B. Evaluating Strain Dependence: We tested another a-synuclein expressing budding yeast strain, TSY623, for its growth in $10 \%$ DMSO condition. Each of the points on the growth curves represents the mean from three trials. In addition, the standard error of the mean for a 95\% confidence interval is represented by the $y$-bar on each of the points on the growth curves.

that expressed GFP alone or contained parent vector were also growth impaired (Figure 4A). Secondly, we evaluated toxicity by serial dilution spotting. Similar to growth curve analysis, we observed a striking dosedependent toxicity with DMSO that was not dependent on the presence of $\alpha$-synuclein (Figure 4B). Because this 10\% DMSO toxicity was unexpected and contrary to published findings [1], we inquired if the toxicity was a result of the sugar source, galactose. However, we found that $10 \%$ DMSO exhibited the same toxicity in cells grown on glucose (Figure 5A.) Lastly, we even considered that the toxic effect of DMSO may be specific to the BY4741 strain. Yet, 10\% DMSO demonstrated the same toxicity in another yeast strain, TSY623 (Figure 5B).

d. DMSO induces $\alpha$-synuclein aggregates and aberrant morphology

Next, we evaluated if DMSO would
induce greater plasma membrane
localization of $\alpha$-synuclein in budding yeast.




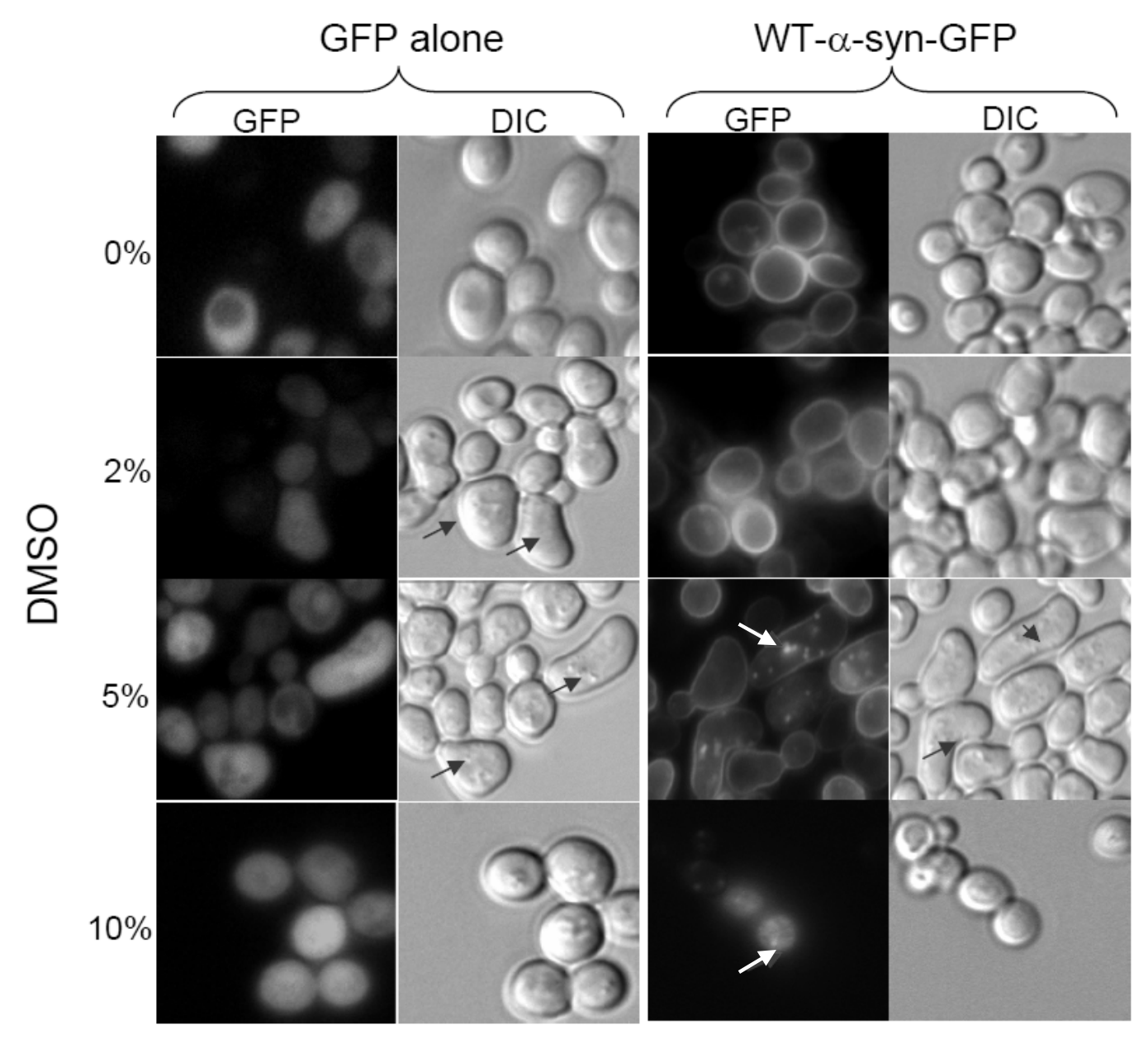

Figure 6. GFP Microscopy of BY4741 treated with DMSO. Images were captured at 18 hours after induction in SC-Ura galactose. Without DMSO treatment, most of the cells showed WT asynuclein localized to the plasma membrane and GFP diffuse in the cytoplasm. With increasing concentrations of DMSO, both GFP and WT cells showed aberrant morphology (dark gray arrow). The aberrant morphological cells expressing WT a-synuclein showed increasing number of cytoplasmic $\alpha$-synuclein aggregates (white arrow).

As previously reported [21], untreated $\alpha-$ synuclein-expressing cells showed $\alpha-$ synuclein localized to the plasma membrane. Images were captured at both 18 and 24 hours post-induction. At 5\% DMSO, two major changes occurred: 1) Cells adopted an aberrant morphology and appeared elongated and sickle-shaped rather than the normal round shape and 2) a-synuclein gained intracellular localization to unknown compartments and was aggregated (Figure 6). Quantification indicated that the aberrant cellular morphology was highest at 5\% DMSO treatment (Figure 7A). Localization patterns indicated that in the normal shaped cells $\alpha$ - synuclein primarily localized to the plasma membrane, while in the abnormal shaped cells it formed cytoplasmic aggregates (Figure 6 and 7B). The expression of $\alpha$ synuclein remained the same with DMSO treatment (Figure 7C).

e. Lack of PS impairs yeast growth

Our third goal was to evaluate whether $\alpha$-synuclein's association with the plasma membrane was specific to a major membrane phospholipid. Moreover, a loss of a major phospholipid, phosphatidylserine (PS), from cellular membranes may change a-synuclein toxicity in budding yeast. PS 
deficiency was achieved by using a yeast strain knocked-out for the $\mathrm{CHO} 1$ gene. This knockout grew significantly slower than the parent strain, BY4741 (Figure 8B). When cells finally started to grow, cho1d strain expressing WT a-synuclein exhibited similar growth curves compared to the control cells (parent plasmid and GFP; Figure 8B).

\section{f. Lack of PS preserves a-synuclein localization}

Nevertheless, we still evaluated $\alpha-$ synuclein localization in cho1 $\Delta$ cells by livecell-GFP imaging to determine if the absence of PS altered a-synuclein's membrane localization. Both at 24 and 36 hours, WT a-synuclein localized to the plasma membrane in cho1 $\Delta$ and the parent strain (Figure 8A), indicating that $\alpha$ synuclein association with the plasma membrane did not solely require PS.

\section{DISCUSSION}

Here, we have examined a-synuclein's interaction with phospholipids as a potential basis for its cellular toxicity. Our first major finding was that DMSO exerted cellular toxicity independent of $\alpha$-synuclein expression along with altering $\alpha$-synuclein's localization and, in budding yeast, changing cellular morphology. Our second major finding was that we found PS to be less critical to a-synuclein's phospholipid membrane binding.

a. DMSO affects viability and influences aberrant cellular morphology

Organic solvents, like DMSO, are known to negatively affect the metabolism of micro-organisms [26]. Previous findings on DMSO treatment to yeast showed that a $10 \%$ concentration in liquid media reduces the cell density by half [1]. In our study, during mid-log phase, $10 \%$ DMSO also reduced the density of fission yeast cells by approximately half. But, to our surprise, this concentration reduced growth by nearly $90 \%$ in two strains of budding yeast. Such a high level of toxicity has not been previously reported. Interestingly, in both types of yeasts, the DMSO toxicity was the highest when $\alpha$-synuclein was also expressed in these cells, suggesting that $\alpha$-synuclein added to the toxicity, but only slightly. $5 \%$ DMSO induced budding yeast (but not fission yeast) to produce abnormal morphologies, reminiscent of cell cycle arrest. The cells are often 2-3 times the normal size suggesting the occurrence of incomplete cytokinesis. In support of this notion, DMSO can convert a haploid yeast strain of Torulaspora delbrueckii into a diploid [27]. Indeed, DMSO can also perturb the mammalian cell cycle, inhibiting the differentiation of myoblasts into muscle cells [28] and the differentiation of $\beta$-lymphocytederived cell line into IgM-producing cells [29]. The mechanism by which DMSO affects yeast cell cycle, cellular morphology, and eventually cellular death remains unknown.

b. DMSO increases a-synuclein's intracellular localization in fission yeast

DMSO has a dramatic influence on a-synuclein cellular localization in both types of yeast. In DMSO treated fission yeast, asynuclein surprisingly does not redistribute from intracellular aggregate to the plasma membrane, which is contrary to our hypothesis. Instead it is found in intracellular locales that are different from and in addition to the usual aggregates. We suggest that the new phospholipids that were induced by DMSO [1] in fission yeast are likely to be intracellular vesicle pools (rather than newly added plasma membrane components). These new phospholipid vesicles bind to $\alpha$ synuclein, redistributing some of it from forming aggregates. It is also possible that some of these internal $\alpha$-synuclein locales are yeast prevacuoles or the vacuole itself, since $\alpha$-synuclein is known to target to the vacuole/lysosome for its degradation [30]. In support of the latter notion, FM4-64 dye, which is a vacuole stain, applied to fission yeast, fluoresces vacuolar membrane structures [31] in a pattern reminiscent of the a-synuclein localization we see in DMSOtreated fission yeast. Though FM4-64 stain was not used in this study, Pellens et al. [32] showed colocalization of FM4-64 stained vesicles with WT $\alpha$-synuclein in yeasts. Lastly, it is also possible that the aggregated pool of $\alpha$-synuclein in fission yeast (seen with and without DMSO) may actually be the result of similar intracellular phospholipid interactions. Our data suggests that such 


\section{A. Quantification [Morphology]}

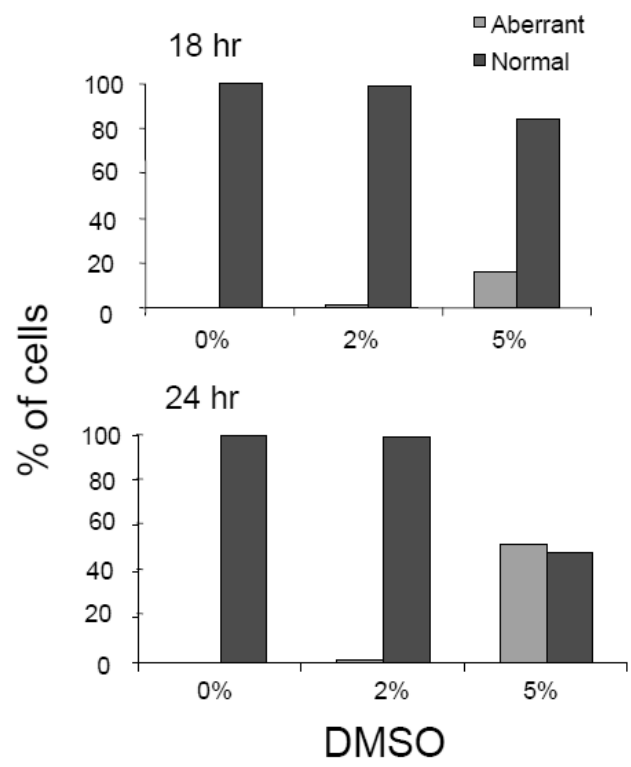

\section{B. Quantification [Localization]}

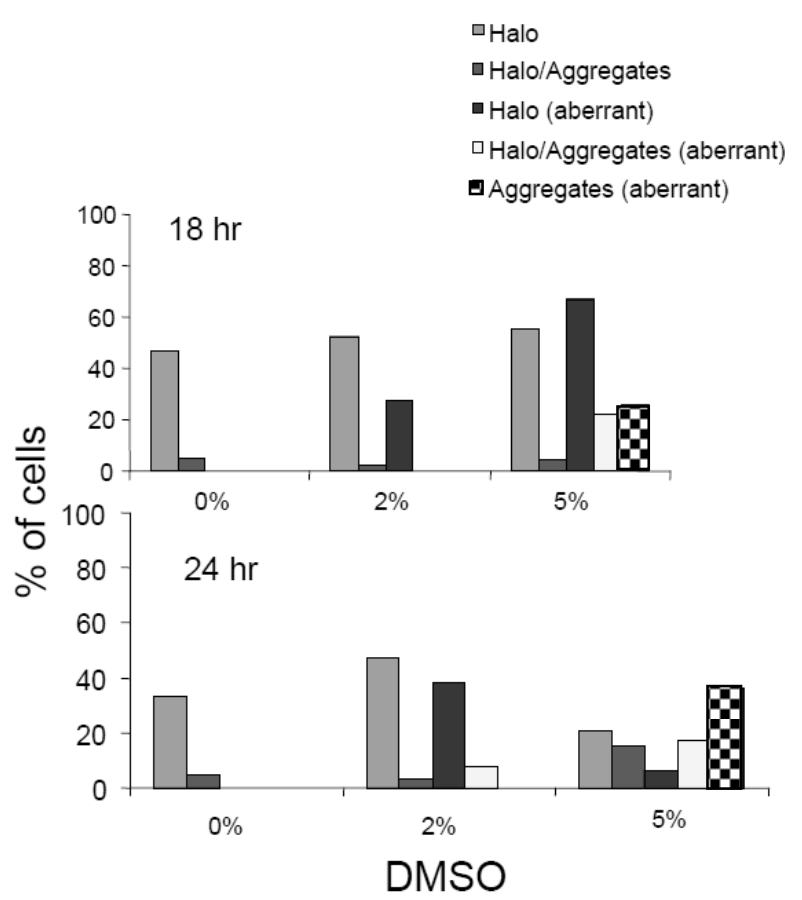

\section{Expression}

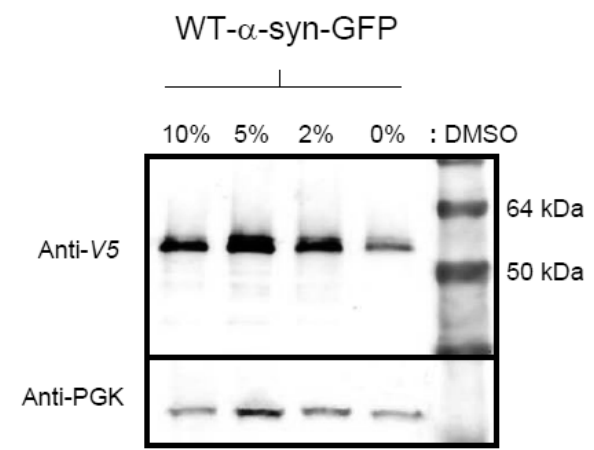

Figure 7. Quantification and a-synuclein expression in budding yeast cells treated with DMSO. A. Quantification of Morphology: DIC images of cells expressing WT a-synuclein were counted and characterized by those showing aberrant morphology (light gray bar) or normal oval shape (light gray bar). Bars represent the percent of 600-800 total cells which display those two different DIC images of the cells at various concentrations of DMSO. The appearance of aberrant morphology increased with a higher concentration of DMSO and over time. B. Quantification of $\alpha-$ Synuclein Localization: Cells expressing WT $\alpha$-synuclein were counted and quantified by those showing halo (light gray bar), halo/aggregates (medium gray bar), halo in aberrant yeast (dark gray bar), halo/aggregates in aberrant yeast (checked bar) or aggregates in aberrant yeast (dark gray bar). Bars represent percent of $600-800$ total cells which display those various $\alpha$-synuclein phenotypes at concentrations of $0 \%, 2 \%$, and 5\% DMSO. C. Expression: For all samples, $\alpha-$ synuclein expression was induced for 24 hours in galactose media and detected using anti-V5. The lower blot was probed with anti-PGK as a loading control. 


\section{A. Microscopy}

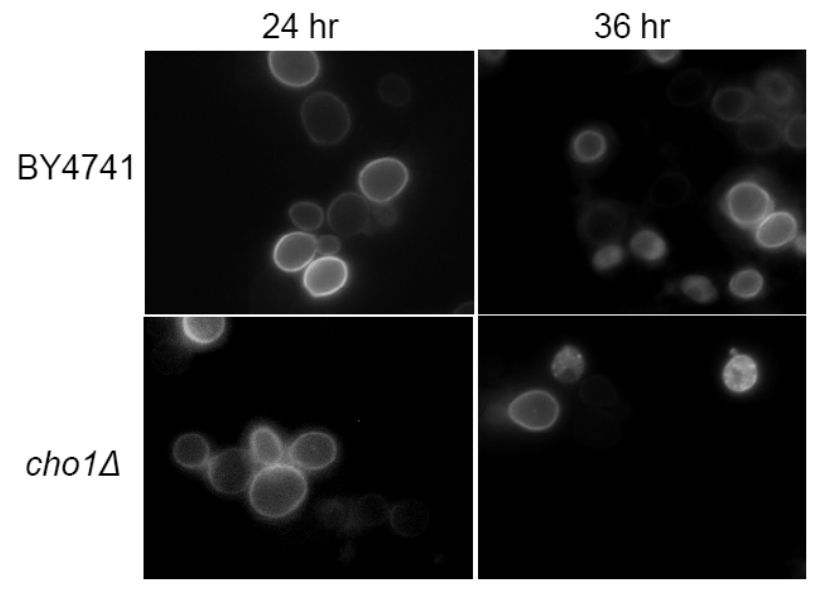

\section{B. Growth Curve}

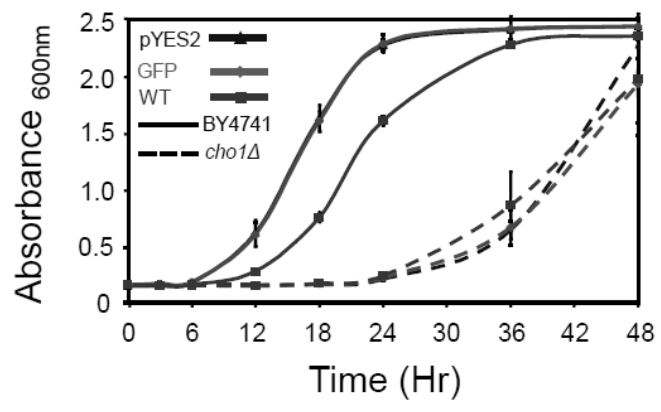

Figure 8. Analysis of cho1 $\Delta$ expressing a-synuclein. A. Microscopy: Images were captured at 24 and 36 hour post-induction in SC-Ura galactose. In CHO1 knockout strain, the WT a-synuclein plasma membrane localization is intact similar to WT a-synuclein in parent strain. B. Growth curve: No observable differences in growth exist between $\alpha$-synuclein expressing cho1 $\Delta$ cells and the cho1 $\Delta$ controls, but significant growth difference exists between BY4741 $\left(n=3, p_{18 h r}=0.004\right.$ and $p_{24 h r}=0.0007$ ) and pYES2 in cho1 $\Delta$ cells. Each of the points on the curves represents the mean from three trials on measurement of absorbance (y-axis). In addition, the standard error of the mean for a $95 \%$ confidence interval is represented by the $y$-bar on each of the points on the growth curves.

membrane interaction appears more important for a-synuclein aggregation, rather than its cellular toxicity. Toxicity may indeed require a-synuclein's plasma membrane localization. Given the lack of $\alpha$-synuclein's plasma membrane localization in fission yeast, it perhaps explains why the $\alpha-$ synuclein addition to DMSO toxicity is at best minimal.

\section{c. DMSO also alters $\alpha$-synuclein localization in budding yeast}

Contrary to our prediction for budding yeast, the localization of $\alpha$ synuclein at the plasma membrane diminished with increasing DMSO levels. Instead, increased pools of intracellular asynuclein aggregates appeared at 2 and $5 \%$ DMSO treatment. We offer two suggestions for this unexpected redistribution. First, like we suggested for fission yeast, DMSO increases $\alpha$-synuclein aggregation in the cytoplasm as a result of increased pool of newly made intracellular phospholipids that do not go to the plasma membrane. Secondly, DMSO is also known to regulate half of the genes in the ergosterol, sphingoglycolipid and fatty acid biosynthetic pathways [26]. This down-regulation may impact $\alpha$-synuclein:lipid interaction in yeast because the $\alpha$-synuclein binds fatty acids and phospholipids [13, 33-36]. In effect, the reduced plasma membrane binding of $\alpha-$ synuclein would result in higher cytosolic concentration of $\alpha$-synuclein, leading it to form non-lipid containing aggregates.

d. Does $\alpha$-synuclein bind to non-PS phospholipids?

In the budding yeast model for PD, a-synuclein localization to the plasma membrane is a prominent feature [21]. In the current study, the localization to the plasma membrane is not lost when PS is eliminated out from the cell. We had expected some, if not all, the reduction of $\alpha$-synuclein's plasma membrane localization, because in vitro $\alpha-$ synuclein binds to PS [36]. But the protein does bind to other phospholipids as well [36], which may explain why a-synuclein remained localized to the plasma membrane in the PS knockout strain. Perhaps, the 
protein's cellular phospholipid binding does not involve PS, or if it does, it's not limited to it. PS is an important phospholipid in yeast growth evidenced by the poor growth of yeast that lack PS. This poor growth prevented us from accurately assessing effects that PS may have had on $\alpha$ synuclein toxicity.

\section{CONCLUSION}

We demonstrate a surprising finding that an organic solvent, DMSO, exerts cellular toxicity and changes morphology in two yeast models we had established for studying Parkinson disease. Budding yeasts exhibit greater vulnerability to DMSO in comparison to fission yeasts. Secondly, DMSO altered $\alpha$-synuclein's localization to yet-unidentified intracellular structures. Our lab speculates that these structures are vacuoles or other phospholipid containing structures. Our future investigation for the link between $\alpha$-synuclein's interaction with phospholipids and cellular toxicity is leading us to explore these future questions: why $\alpha-$ synuclein forms non-toxic cytoplasmic aggregates? Why does it not localize to the plasma membrane in fission yeast? Are other major membrane phospholipids, such as phosphatidyl choline (PC), phosphatidyl ethanolamine (PE), and phosphatidyl inositol (PI) critical to $\alpha$-synuclein plasma membrane localization?

\section{ACKNOWLEDGMENTS}

We thank Michael White and Michael Fiske for their editorial comments. We also thank Sara Herrera, Katrina Brandis, Michael Zorniak, Stephanie Valtierra, Alex Ayala, Alina Konnikova and Julian McLain for their support during laboratory bench work. L.K. was supported by a summer Parkinson Disease Foundation fellowship. S. D. was supported by grants from NIH (R15 NS048508) and NSF (CCLI 0310627 and MRI 0115919).

\section{REFERENCES}

1. Murata et al. (2003) Dimethyl Sulfoxide Exposure Facilitates Phospholipid Biosynthesis and Cellular Membrane Proliferation in Yeast Cells. JBC 278(35): 33185-33193.
2. Chua, C. E. L., and Tang, B. L. (2006) alpha-Synuclein and Parkinson's disease: the first roadblock. J. Cell. Mol. Med., 10(4): 1-10.

3. Eriksen et al. (2003) Caught in the Act: alpha-Synuclein Is the Culprit in Parkinson's Disease. Neuron, 40: 453456.

4. Spillantini M., Schmidt M., Lee V., Trojanowski J., Jakes R., and Goedert M. (1998) a-Synuclein in filamentous inclusions of Lewy bodies from Parkinson's disease. Proc. Natl. Acad. Sci. 95: 6469-6473.

5. Polymeropoulos et al. (1997) Mutation in the a-synuclein Gene Identified in Families with Parkinson's Disease, Science, 276: 2045-2047.

6. Kruger et al. (1998) Ala30Pro mutation in the gene encoding $\alpha$-synuclein in Parkinson's disease, Nature Genetics, volume 18: 106-108.

7. Zarranz JJ et al. (2004) The new mutation, E46K, of alpha-synuclein causes Parkinson and Lewy body dementia, Annals of Neurology, 55(2): 164-173.

8. Masliah et al. (2000) Dopaminergic loss and inclusion body formation in alphasynuclein mice: implications for neurodegenerative disorders, Science, 287: 1265-1269.

9. Feany M. and Bender W. (2000) A Drosophila model of Parkinson's disease. Nature, 23: 294-298.

10. Rochet J. C., Outeiro T. F., Conway K. A., Ding T. T., Volles M. J., Lashuel H. A., et al. (2004) Interactions among alpha-synuclein, dopamine, and biomembranes: some clues for understanding neurodegeneration in Parkinson's disease. J. Mol. Neurosci. 23: 23-34.

11. Scherzer, C. R., and Feany M. B. (2004) Yeast genetics targets lipids in Parkinson's disease. Trends in Genetics 20(7): 273-277.

12. Soper et al. (2008) a-Synuclein-induced aggregation of cytoplasmic vesicles in Saccharomyces cerevisiae, Molecular Biology of the Cell, 19: 1093-1103.

13. Kaplan, B., Ratner, V., and Haas, E. (2003) a-Synuclein: Its Biological Function and Role in Neurodegenerative Diseases. Journal of Molecular Neuroscience. 20: 83-92. 
14. Kahle et al. (2000) Subcellular Localization of Wild-Type and Parkinson's Disease-Associated Mutant -Synuclein in Human and Transgenic Mouse Brain. The Journal of Neuroscience, 20(17): 6365-6373.

15. Dixon et al. (2005) alpha-Synuclein Targets the Plasma Membrane via the Secretory Pathway and Induces Toxicity in Yeast. Genetics, 170: 47-59.

16. Outeiro T. F. and Lindquist S. (2003) Yeast cells provide insight into alphasynuclein biology and pathobiology. Science 203: 1772-1775.

17. 17. Volles, M. J., and Lansbury, P. T. Jr. (2007) Relationships between the Sequence of alpha-Synuclein and its Membrane Affinity, Fibrillization Propensity, and Yeast Toxicity. J. Mol. Biol., 366: 1510-1522.

18. Zabrocki P., Pellens K., Vanhelmont T., Vandebroek T, Griffioen G., Wera S., et al. (2005) Characterization of $\alpha-$ synuclein aggregation and synergistic toxicity of protein tau in yeast. FEBS J. 272, 1386-1400.

19. Cooper et al. (2006) a-synuclein Blocks ER-Golgi Traffic and Rab1 Rescues Neuron Loss in Parkinson's Models. Science 313(5785): $324-328$.

20. Willingham S., Outeiro T. F., DeVit M. J., Lindquist S., and Muchowski, P. J. (2003) Yeast genes that enhance the toxicity of a mutant huntingtin or asynuclein. Science 302, 1769-1772.

21. Sharma N., Brandis K., Herrera S., Johnson B., Vaidya T., and DebBurman S. K. (2006) a-Synuclein budding yeast model: toxicity enhanced by impaired proteasome and oxidative stress. J. Mol. Neurosci. 28(2), 161-178.

22. Brandis, K. A., Holmes, I. F., England, S. J., Sharma, N., Kukreja, L., and DebBurman, S. K. alpha-Synuclein fission yeast model: concentration dependent aggregation without plasma membrane localization or toxicity, Journal of Molecular Neuroscience, volume 28, pages 179-191, 2006.

23. Alfa et al., eds. (1993) Experiments with Fission Yeast, Cold Spring Harbor Laboratory Press, Cold Spring Harbor, New York.

24. Burke D., Dawson D., and Stearns T. (2000) Methods in Yeast Genetics, Cold
Spring Harbor Laboratory Press, New York.

25. Carman G. M. and Zeimetz G. M. (1996) Regulation of Phospholipid Biosynthesis in the Yeast Saccharomyces cerevisiae. JBC, 271(23): 13293-13296.

26. Zhang et al. (2003) Microarray analyses of the metabolic responses of Saccharomyces cerevisiae to organic solvent dimethyl sulfoxide. J Ind Microbiol Biotechnol, 30: 57-69.

27. Sasaki T. and Ohshima Y. (1987) Induction and Characterization of Artificial Diploids from the Haploid Yeast Torulaspora delbrueckii. Applied And Environmental Microbiology. 53(7): 1504-1511.28.

28. Blau H. M. and Epstein C. J. (1979) Manipulation of Myogenesis in Vitro: Reversible Inhibition by DMSO. Cell, 17: 95-108.

29. Teraoka et al. (1996) Reversible G1 Arrest Induced by Dimethyl Sulfoxide in Human Lymphoid Cell Lines: Dimethyl Sulfoxide Inhibits IL-6-Induced Differentiation of SKW6-CL4 into IgMSecreting Plasma Cells. Experimental Cell Research, 222: 218-224.

30. Cuervo et al. (2004) Impaired Degradation of Mutant-Synuclein by Chaperone-Mediated Autophagy. Science 305(5688): 1292-1295.

31. Gachet Y. and Hyams J. S. (2005) Endocytosis in fission yeast is spatially associated with the actin cytoskeleton during polarized cell growth and cytokinesis. Journal of Cell Science, 118: 4231-4242.

32. Pellens K., Zabrocki P., Vanhelmont T., Vandebroek T., Griffioen G., Wera S., Van Leuven F. and Winderickx J. (2005) Components Enhancing a-synuclein Aggregation and Toxicity in a Humanized Yeast in: New trends in Alzheimer and Parkinson related disorders: ADPD: 25-29.

33. Sharon, R. et al. (2003) The Formation of Highly Soluble Oligomers of alphaSynuclein Is Regulated by Fatty Acids and Enhanced in Parkinson's Disease. Neuron, 37: 583-595.

34. Salem et al. (2007) An investigation into the lipid-binding properties of alpha-, beta- and gamma-synucleins in human 
brain and cerebrospinal fluid. Brain research, 1170: 103-111.

35. Davidson et al. (1998) Stabilization of alpha-Synuclein Secondary Structure upon Binding to Synthetic Membranes.

The Journal of Biological Chemistry,
273(16): 9443-9449.

36. Jo et al. (2000) alpha-Synuclein Membrane Interactions and Lipid Specificity. The Journal of Biological Chemistry, M004345200: 1-43.

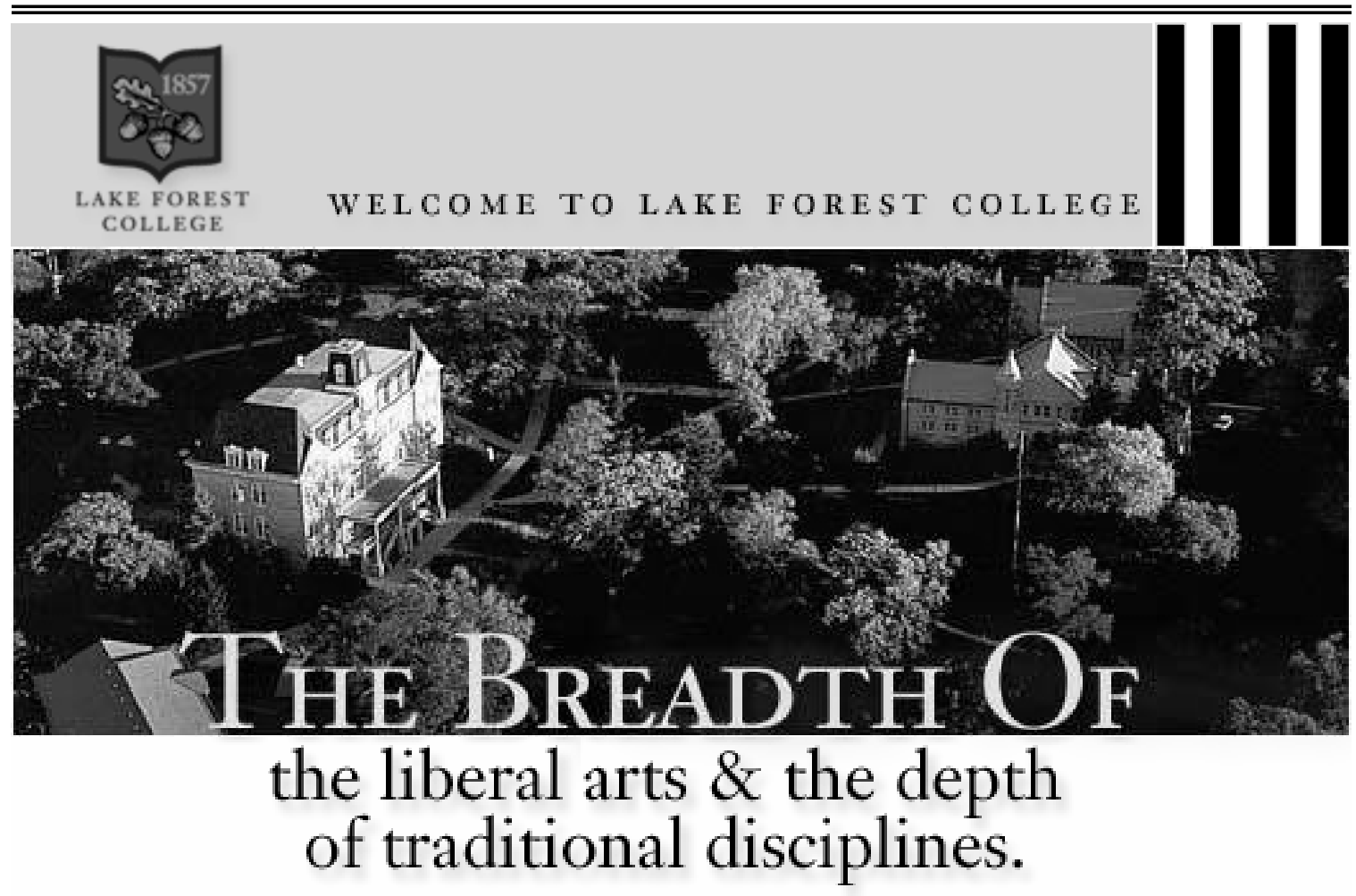

\section{Chicago's National Liberal Arts College}

Lake Forest College is a coeducational undergraduate institution located just $\mathbf{3 0}$ miles north of Chicago in the small city of Lake Forest, Illinois. One of the most beautiful suburbs on Chicago's North Shore, Lake Forest provides a secure, supportive environment for the College. The beautiful 107-acre campus sits just a few blocks from Lake Michigan and is within walking distance of the train station and the shops, cafés, and restaurants of downtown Lake Forest.

At the heart of the College is the close-knit community of teachers, scholars, students, and staff representing cultures from around the globe who live, learn, and work together in an environment of mutual respect and collaboration. A national liberal arts college, Lake Forest prides itself on diversity, with students representing 45 states and 65 countries.

The distinguished faculty, 98 percent of whom hold a PhD or equivalent degree, are committed to teaching undergraduates. Faculty members, rather than graduate assistants, teach all classes and provide academic advising. Faculty members are also active scholars who have won national teaching awards and have spoken and consulted throughout the United States and abroad. More than 30 percent have published books in their discipline.

www.lakeforest.edu 